\title{
Density Dependence, Territoriality, and Divisibility of Resources: From Optimality Models to Population Processes
}

\author{
${\text { Christiaan } \text { Both }^{1,2, *} \text { and Marcel E. Visser }}^{1}$ \\ 1. Netherlands Institute of Ecology, P.O. Box 40, 6666 ZG \\ Heteren, The Netherlands; \\ 2. Zoological Laboratory, University of Groningen, P.O. Box 14, \\ 9750 AA Haren, The Netherlands
}

Submitted November 26, 2001; Accepted July 17, 2002;

Electronically published February 5, 2003

\begin{abstract}
Species differ enormously in their territorial systems. Some species defend only small areas surrounded by undefended space, while others defend large contiguous territories. Using an optimization approach, we show that this variation can be explained from the density of two types of resources: divisible and nondivisible. We assume that benefits of territories are monotonously related to the defended amount of divisible resources (hereafter called food). In contrast, no benefits are obtained without a nondivisible resource (hereafter called nest site) in the territory, while more than one nest site does not further increase the benefits. The optimal territory size depends on the relative abundance of these resources. With a low density of nest sites, the optimal territory size is small and includes only the nest site. If the density of nest sites is relatively large, the optimal territory size is high, and territories are contiguous. Competition for these different resources yields contrasting patterns of how populations are regulated. If there is mainly competition for nest sites, we expect density-dependent exclusion through territoriality and no density-dependent reproduction. When competition is mainly for food, we expect density-dependent reproduction because optimal territory size will be compressed at higher densities, resulting in lower reproductive success. These predicted patterns indeed are observed in some well-studied passerine species for which both the territorial system and the occurrence of density dependence is known.
\end{abstract}

Keywords: density dependence, territory, divisible resource, optimality model, nest site, bird.

\footnotetext{
* Corresponding author; e-mail: C.Both@nioo.knaw.nl.
}

Am. Nat. 2003. Vol. 161, pp. 326-336. (c) 2003 by The University of Chicago. 0003-0147/2003/16102-010410\$15.00. All rights reserved.
Territoriality is an important process in population dynamics and the distribution of individuals over a habitat (Hinde 1956; Brown 1964; Lack 1966). One of the first observations on how territoriality affects bird populations was that at low population densities, all individuals were confined to high-quality habitat and that increasing population density resulted in more individuals settling in high-quality but not low-quality habitat (Kluyver and Tinbergen 1953). This implies that some mechanism exists that distributes numbers over patches of varying quality (Fretwell and Lucas 1969). Territorial behavior was hypothesized to be the mechanism preventing new individuals settling in a high-quality habitat, and this now has been demonstrated by numerous experiments (Newton 1992). Territoriality stabilizes population numbers if more individuals are excluded at high than at low densities (Watson and Moss 1970), which has been shown in several studies (Southern 1970; Nilsson 1987; Newton 1988; Smith et al. 1991).

Species vary to a large extent in the degree to which they are territorial. Some species always defend large territories that border neighboring territories, preventing other individuals from establishing a territory. Other species do so in high-density years but not in low-density years, and still other species always defend small territories with nondefended space between territories. As examples of these three modes of territoriality, we consider the wellstudied great tit Parus major, the blue tit Parus caeruleus (Dhondt et al. 1982), and the pied flycatcher Ficedula hypoleuca (von Haartman 1956). All three bird species are secondary hole-nesting species and co-occur over much of Temperate Zone Europe.

Variation in territorial systems described above should have important consequences in how population numbers are regulated. Interestingly, the degree to which densitydependent reproduction is found in the great and the blue tit and the pied flycatcher co-varies with their territorial system (fig. 1). Great tits with large contiguous territories have strong density-dependent reproduction (Kluyver 


\section{Great tit}
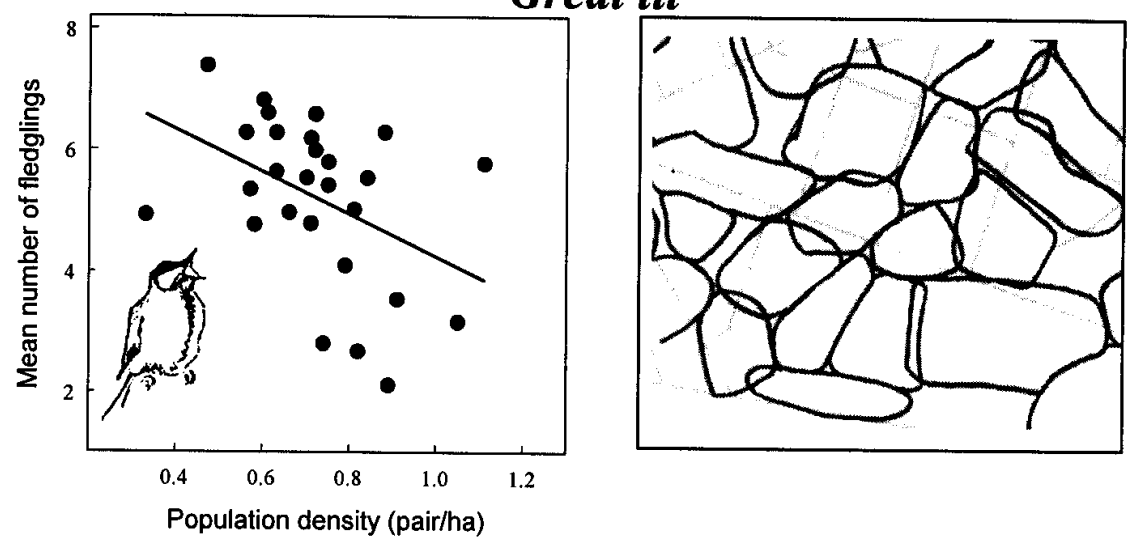

\section{Blue tit}
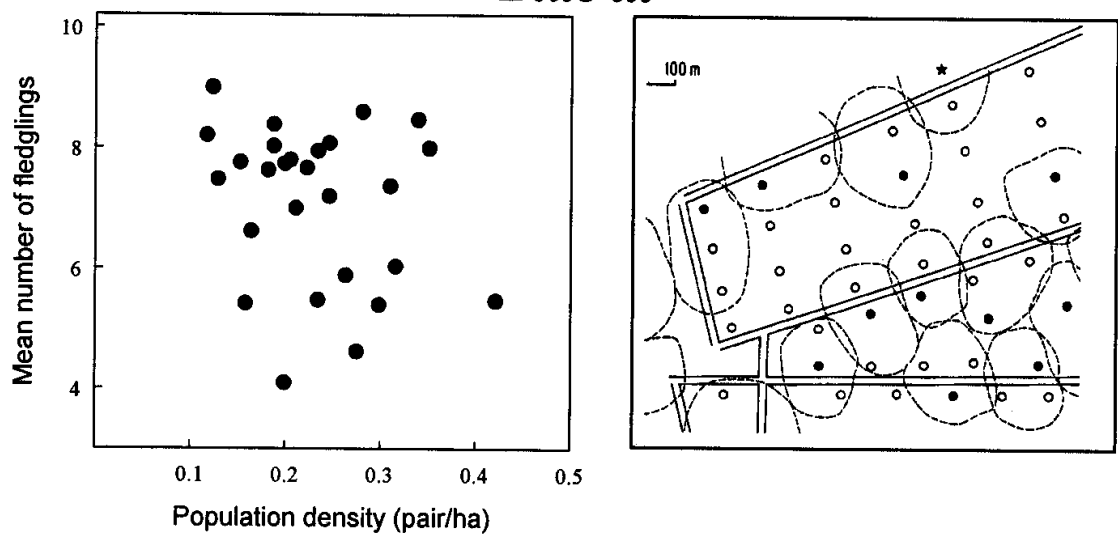

Population density (pair/ha)

\section{Pied Flycatcher}
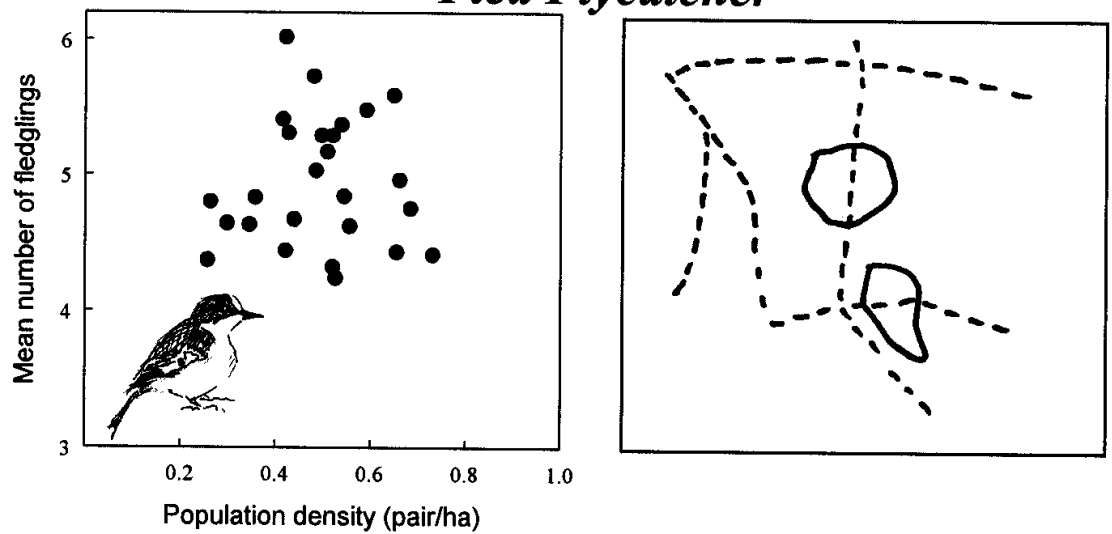

Figure 1: Territorial systems and the occurrence of density-dependent reproductive output in three cavity-nesting passerine species. For each species, we depict a map with territory boundaries and the annual number of fledged chicks from first broods in the nest boxes in the Hoge Veluwe area (Netherlands) as a function of the breeding density in the nest boxes (1973-1999). The territory map of great tits in a nearby area is from our own work; the blue tit map is from Dhondt et al. (1982). The flycatcher map is redrawn from von Haartman (1956; our interpretation of his maps 4 and 5). Reproductive success was significantly density dependent for the great tit $(F=5.54, \mathrm{df}=1,25, P=.03)$ but not for the blue tit $(F=$ 1.61, $\mathrm{df}=1,25, P=.22)$, nor for the pied flycatcher $(F=0.57$, $\mathrm{df}=1,25, P=.46)$. 
1951; van Balen 1973; Both 1998b; Both et al. 2000), while density-dependent reproduction is rarely observed in the pied flycatcher defending small territories (Tompa 1967; Alatalo and Lundberg 1984; Stenning et al. 1988). Blue tits take an intermediate position, with density-dependent reproduction being found in some but not all populations (van Balen and Potting 1990; Dhondt et al. 1992; Both 2000). We have two aims in this article: to explain why some species cover an entire habitat with territories while others only defend small, noncontiguous territories and to show how density dependence of reproductive success within and among species can be a consequence of these types of territoriality. We approach these questions by developing models of optimal territory size under different ecological conditions.

\section{Approach}

Ultimate explanations of why species, or individuals within species, differ in their territorial system should focus on both the associated costs and the benefits (Davies and Houston 1984). This economic approach to territory size has been successfully applied to feeding territories, showing that the optimal territory size changes when benefit or cost curves are changed (Gill and Wolf 1975; Davies and Houston 1981; Schoener 1983). Although the same logic applies to breeding territories, we will include two additional considerations in our models. First, in breeding territories the resources are partially converted into offspring rather than used only for self-maintenance, and therefore the benefit curve lacks a clear upper level as long as the food can be brought to the nest. The second is that the nest is a central place to which part of the food has to be transported (Orians and Pearson 1979), and although a larger territory has more resources, the transport time causes the benefit curve to level off. In our approach, we thus do not consider the mere energetics to be the optimization currency for territory size but instead to be a fitness measure (i.e., offspring production).

Territoriality and density dependence are tightly linked, in such a way that the former is a resolution of resource competition between individuals, and the latter is the consequence of this competition at the population level. The resources competed for in feeding territories are food particles that can be divided between individuals. A characteristic of these divisible resources is that the benefits gradually increase with the monopolized amount of resources (Stamps and Krishnan 2001). Besides these divisible resources, breeding territories may also contain nondivisible resources, which are all-or-nothing resources for reproduction that cannot be divided between individuals. An example of such a nondivisible resource is a nest site; in most species, reproductive success is approximately 0 with- out a nest site and is not shared with other pairs. In the rest of this article we will call the divisible resource "food" and the nondivisible resource "nest site." In contrast to the gradual increase with food, a step function will describe reproductive success in terms of the availability of nest sites. Note that more than one nest site does not increase reproductive success. In our models, the densities of both food and nest sites are important in explaining the variation in territorial systems and the occurrence of densitydependent reproduction.

\section{The Economics of Breeding Territory Size Determined by Food Only}

When territory size increases, the amount of food it contains increases, but so do the costs of defending it. An optimal territory size is where the benefits minus the costs is maximized, and the optimal territory size thus depends on how benefits and costs increase with territory size. Here we assume that all individuals in the population have a territory and that no individuals are excluded from breeding by territoriality. This means that the territory size, with contiguous territories, is determined only by the population size. Despite this, we choose to use an optimality model to make clear what the consequences of competition for food or nest sites are and how this competition leads to density-dependent patterns in reproduction. This model also enables us to investigate the effects of variation in cost and/or benefit curves (see appendix). We realize that the assumption of all individuals obtaining a territory is unrealistic in most systems and that realistic models should include strategies of "floaters" that are excluded from territories. However, the main message of this article is not affected by this assumption.

In a homogeneous habitat, the amount of food a territory contains is linearly related to its area. The amount of food that can be brought to the nest and transferred into offspring depends on the transporting time to the nest and the time it takes to find a food item. An increase in territory size thus gives more food but also increases the average distance of the food to the nest, and hence the benefits should increase with diminishing returns. We assume a proportional relationship between the amount of food brought to the nest and reproductive output, and the benefits are expressed as the number of offspring raised. We can describe this relationship between benefits and territory size in the following way:

$$
\text { benefits }=b-\frac{b}{T+1}
$$

where $b$ is the asymptotic benefit (which may vary either among individuals or habitats), and $T$ is the territory size. 
This curve starts in the origin and increases with territory size and with a decelerating slope (fig. 2). Although the curve is asymptotic as in models of feeding territories (Gill and Wolf 1975), the asymptote is not defined as a fixed maximum intake above which fitness no longer increases. This is because the asymptotic benefits of a breeding territory increase if individuals are better foragers (Lemon 1993) or if the habitat has a higher food density (Arcese and Smith 1988).

As territories increase, their circumference increases, and more potential settlers are excluded from the territorial population. The increase in circumference results in more patrolling time and hence a decrease in foraging time, but the circumference per unit territory declines. Additionally, the pressure of potentially excluded individuals is an important cost of a larger territory, especially because the same size area yields a higher benefit for an individual without a territory than for a territorial individual that already has a certain area as a result of the diminishing return in the benefit curve. For a given population size, we assume that the cost of territory defense is linearly related to territory size but that those costs increase with increasing population density:

$$
\text { costs }=M+\frac{f(N-1)}{d} T \text {. }
$$

Because each individual needs resources for survival even without defending a territory, we consider a maintenance cost $M$. Individuals may differ in their capacity to defend a territory of a certain size, which is captured in $d$ (a larger $d$ makes the cost lower, and an individual is thus better in territory defense). The effect of population size $f(N-1)$ is captured in a scaling function enabling all individuals to defend a territory within the available area. We solve this function by iteration. The effect of population size is that in larger territories the costs increase, and therefore the optimal territory size decreases. The costs can be expressed as the decrease in current reproductive success due to territory defense or as a decrease in future reproductive success.

Costs and benefits of territory defense are both expressed in terms of fitness, and the overall fitness payoff is the benefits minus the costs. The optimal territory size (fig. 2) is where

$$
\frac{d f}{d T}=\frac{b}{(T+1)^{2}}-\frac{f(N-1)}{d}=0
$$

which is

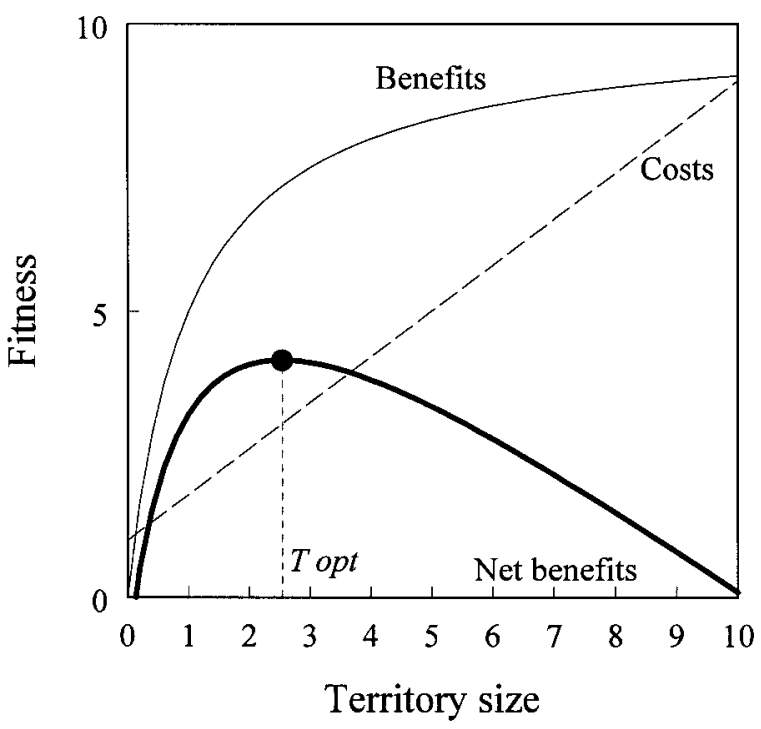

Figure 2: Costs and benefits as a function of territory size when food is the only competed resource, according to equations (1)-(4). The net benefits (fitness) are the benefits minus the costs. The thin unbroken line is the benefit curve, the broken diagonal line is the cost curve, and the black solid line is the net benefit curve. $T_{\text {opt }}$ is the territory size that maximizes fitness. Parameters in the model: $b=10, d=2, f(N-$ 1) $=1.6, M=1$.

$$
T_{\mathrm{opt}}=\sqrt{\frac{d \times b}{f(N-1)}}-1
$$

Optimal territory size thus increases if individuals are better in defense (higher $d$ ) or better in foraging (higher $b$ ), and it decreases with the number of competitors $(f[N-$ 1]).

In this economic model of breeding territory size, the underlying curves are difficult to measure in reality because variation in territory size is expected to be due to different curves rather than to individuals defending a suboptimal territory size (see appendix). So far the model has been based on the class of divisible resources, and we now expand the model with nondivisible resources (e.g., a nest site).

\section{Optimal Breeding Territory Size with Food and Nest Sites}

Nestling food is not the only resource that matters for a bird defending a breeding territory. If there is no suitable nest site in the territory, the pair cannot breed, and therefore their current reproductive success (i.e., benefits) is 0 . A nondivisible resource such as a nest site is thus an important determinant of reproductive success.

If a territory does not contain a nest site, the benefits 
are 0 , but costs are being paid to defend the territory, and therefore the total fitness payoff is negative (fig. 3 ). If the density of nest sites is so high that a territory based on divisible resources will always have a nest site, the optimal territory size does not change compared to our earlier model (fig. $3 A$ vs. fig. 2 ). If the density of the nest sites is lower and the territory size based on food is too small to contain at least a single nest site, the optimal territory size is in principal based on the density of nest sites (fig. $3 B$; optimal territory size being $1 /[$ nest density], nests assumed to be uniformly distributed). In this case, there are more pairs than there are available nest sites, and therefore not all pairs can breed. Because it is costly for pairs to defend a territory without a nest site (costs without any benefits), pairs with a nest site can cease defending a large territory and concentrate on defending the nest site only. The reason is that without the ownership of a nest site, the space between nest sites is worthless and therefore will not be defended by any individual. All individuals will concentrate on competing for the limited nest sites, and the result is a system where only small territories around a nest site are defended. There thus occurs a shift from large contiguous territories to small noncontiguous territories when the density of nondivisible resources decreases relative to the density of divisible resources.

Individuals sometimes breed in a low-quality habitat with low reproductive success without settling in a rich habitat, and they therefore do not affect the reproductive success in this high-quality habitat (Dhondt et al. 1992; Ferrer and Donazar 1996; Rodenhouse et al. 1997). This may be because of individual quality differences, but it can also be caused by the distribution of nest sites. We assume a rich and a poor habitat in food availability but with an equal density of nest sites (fig. 4). If this nest-site density is so low that it determines the territory size, then individuals that lose the competition for a nest site in the rich habitat can best breed in the poor habitat with lower reproductive success without affecting reproductive success in the rich habitat. A rich habitat seems to have a large amount of undefended space, while individuals settle in the poor habitat with low reproductive success.

Whether the territorial system is determined by food or nest sites can change from year to year depending on the competitor density and the density of food and nest sites. In high population density years when the costs of territory defense are high, the optimal territory size based on food may be smaller than the nest-site density, and during such a year, the territorial system may break down as individuals defend only their nest site (fig. 5). In contrast, low population density years have relatively lower territory defense costs, and the density of nest sites does not limit the number of breeders. During such a year, we expect large contiguous territories to be defended (fig. 5). Similar effects
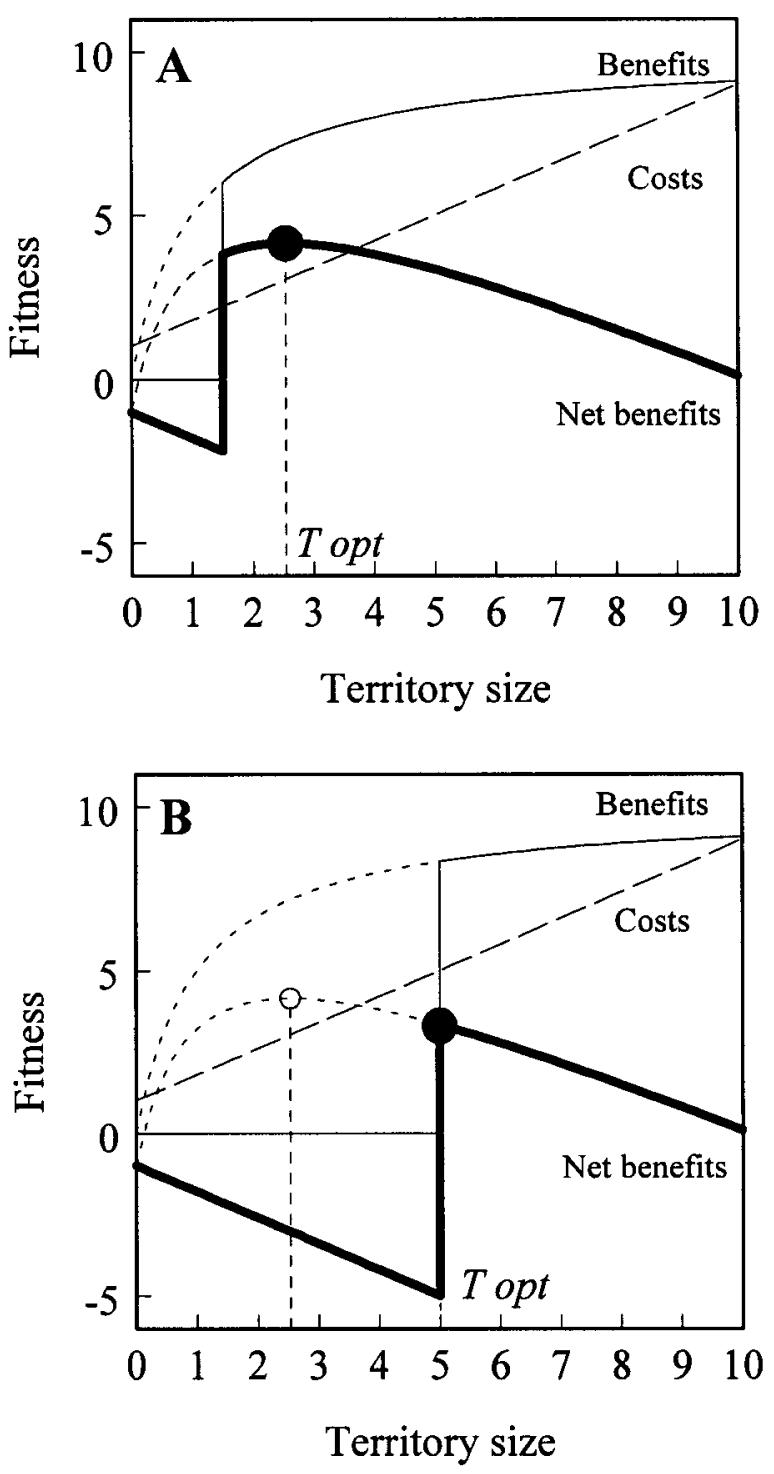

Figure 3: Optimal territory size when both food and nest sites are included: in $A$, food determines optimum; in $B$, nest sites determine optimum. Optimal territory size is marked by the solid dot and $T_{\mathrm{opt}}$. In $A$, nest-site density is one per 1.5 unit of surface; in $B$, it is one per 5.0 units of surface. Beyond this point, costs are being paid without a gain in benefits. The thin unbroken line is the benefit curve, the broken diagonal line is the cost curve, and the black solid line is the net benefit curve. In $A$ and $B$, dashed lines represent the benefit and net benefit curves in case there would have been no nest-site limiting; in $B$, the optimal territory size without nest-site limitation is depicted by the open dot. Parameters in the model are as in figure 2.

can occur when nest sites are not uniformly distributed but instead are spatially clumped. In such a case, individuals are expected to defend only the nest site in both the parts with low and high nest-site density for as long as the nest-site density is low compared to the number of 


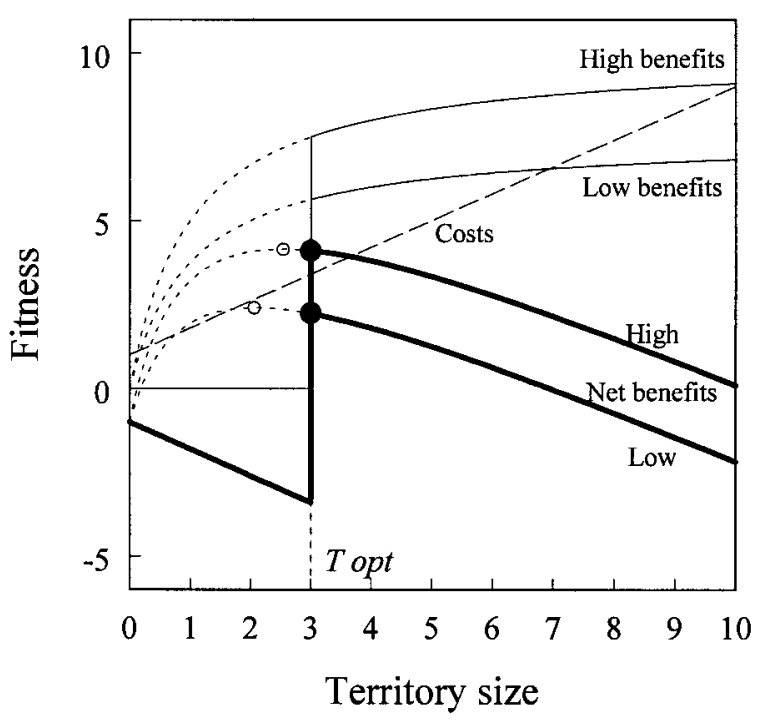

Figure 4: Optimal territory size when food and nest sites are included and two habitats differ in food abundance $(b)$. The model parameters and symbols are as in figure 2 , but in the poor habitat, $b=7.5$, while in the rich habitat, $b=10.0$. Although the different habitats differ in benefit curve and in the optimal territory size if only food was included (open dots), the territory sizes are equal because of equal density of nest sites (one nest site per 3 units of surface).

individuals competing for a territory. In the high nest-site density part, this is because the defense costs rise steeply with the number of competitors, and therefore the optimal territory size based on food decreases only to values lower than those based on the density of nest sites.

\section{Territorial Systems and Density-Dependent Reproduction}

We expect that density-dependent reproduction is rare in populations where the availability of nest sites determines territory size and population density of breeders. In these populations, the breeding density will probably fluctuate less compared to a population with a high density of nondivisible resources because a clear upper limit is set to breeding density by the availability of nest sites. Furthermore, most variation in reproductive success is expected in the range of small territories because of the decelerating benefit function (fig. 2), and variation in reproductive success will therefore be less if territories are fluctuating in size with a higher mean. Density-dependent reproduction will thus be related to the territorial system, which in turn is affected by the relative densities of food and nest sites. Populations that are affected most by the nest-site density are expected to have a stronger density-dependent effect on the likelihood of breeding because of the strong com- petition for these nest sites. Populations mostly affected by the food density have, on average, larger and contiguous territories, and density-dependent reproduction is expected.

\section{Discussion}

\section{Explaining Variation in Territorial Systems}

Our models include both nest sites and food as resources for which competition takes place. The models can explain the variety of territorial systems, ranging from small territories that mainly contain the nest site (e.g., as found in pied flycatchers; von Haartman 1956) to the large contiguous territories that contain most of the food (e.g., as found in the great tit; Hinde 1952; Krebs 1971; fig. 1). All these species are hole nesting where competition for nest holes is well known. The difference between these species is that great tits normally have priority over nest sites because of their larger size and their residential status. In areas with a high density of nest holes, most great tit populations have density-dependent reproduction (Kluyver 1951; van Balen 1973; Both 1998a, 1998b; Both et al. 2000). However, in areas where nest holes are sparse, great tits will breed with two or three pairs in the same tree when nest boxes are clumped (Löhrl 1987). Although it

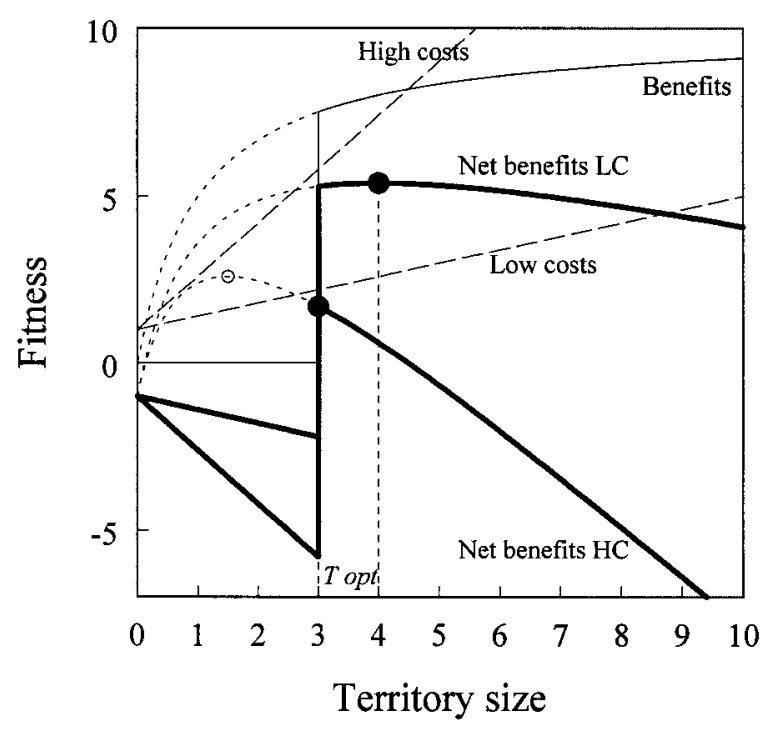

Figure 5: Optimal territory size when food and nest sites are included and years differ in competitor density $(f[N-1])$. The model parameters and symbols are as in figure 2, but in the high competitor year, $f(N-$ $1)=3.2$; while in the low competitor year, $f(N-1)=0.8$. With this density of nest sites (one nest site per 3 units of surface), the individuals in the low competitive year will defend a large-sized territory, while in the high competitive year, they have a larger territory than one based on food only and therefore concentrate on defending only the nest site. 
is unknown what the birds' territorial system is in this case, the results suggest that a change may occur when nondivisible resources are limiting.

The smaller blue tit defends large contiguous territories in areas with a high density of the nondivisible resource (nest boxes), but in an area with a low density of nest boxes, their territories are small and noncontiguous (Dhondt et al. 1982). This may be explained by spatial variation in the relative importance of food and nest sites, the latter being more important for blue tits than great tits because blue tits normally lose in nest-hole competition with the larger great tits (Dhondt and Eyckerman 1980; Minot and Perrins 1986). Blue tit reproductive success in high-quality territories is not strongly affected by the overall breeding density, but at high population density, more individuals settle in low-quality territories with lower reproductive success (Dhondt et al. 1992), as expected when nest sites are an important factor in the territorial system. In contrast, the pied flycatcher seems never to defend large contiguous territories, but instead, young birds delay reproduction in high-density years, probably as a result of competition for nest sites (C. Both, M. E. Visser, and J. H. van Balen, unpublished manuscript). Pied flycatchers also do not defend larger territories when the density of artificial nest boxes (the most likely nondivisible resource) is very high (von Haartman 1956). This latter observation contradicts our predictions, but it may be that pied flycatchers have mostly evolved in situations where nest sites were limiting through competition with other species; perhaps, in their evolutionary history, no benefit came of having a flexible territorial system. Under extremely high densities, the reproductive success declines in years with adverse weather conditions (Alatalo and Lundberg 1984), suggesting that under these circumstances, it benefits the birds to defend larger territories to monopolize enough food.

So far, we considered the type of territoriality as a species-specific trait, but some evidence exists of intraspecific variation across habitats. Great tits breed at low densities in natural woodlands in eastern Europe, probably due to high mortality rather than nest-site limitation (Wesolowski et al. 1987). In the Mediterranean region, great tits live at much lower densities than in western Europe and are outnumbered by blue tits (Doutrelant et al. 2000). Under such low densities, the costs of territory defense are low, increasing only slightly with territory size. As a result, the great tits may not defend clearly defined and contiguous territories, while the blue tits breeding in the same area at high densities may instead defend large contiguous territories.

The relative density of food and nest sites can explain variation in territorial systems as observed in hole-nesting species, but this also may apply to other species. Artificially increasing nest-site density has resulted in crows Corvus corone becoming territorial in areas that were previously frequented only by groups of nonterritorial individuals (Charles 1972, reference in Newton 1992). This shows that territory defense does not take place in areas in which nest sites are lacking. Choughs Pyrrhocorax pyrrhocorax with dispersed nest sites do defend territories, in contrast to choughs in areas with clustered nest sites where breeding individuals forage in flocks (Blanco et al. 1998); this again shows a change in the territorial system coming out of a change in the relative density of the different resources. Another example of the importance of the density of nest sites relative to food is the provisioning of artificial nest sites for kestrels Falco tinnunculus. In one habitat, this leads to an increase in density while in another area, no effect was observed (Village 1983, 1990). It can be hypothesized that in the former area, the territory size was determined by nest sites, while in the other area, the food determined territory size. In contrast, in most open-nesting species, the nest sites may not limit the breeding population size, and both large contiguous territories and density-dependent effects on reproductive success are expected (Catterall et al. 1982; Arcese et al. 1992).

\section{From Territoriality to Population Dynamics}

An intricate link exists between territoriality and population regulation. At low densities, all individuals in a population are able to establish a territory in high-quality habitat. Territories are large and reproduction is high. With increasing density, the costs of territory defense increase, causing territory size to shrink. Reproduction declines, and individuals settle in poorer habitats that initially had lower reproductive success. Such a switch to lower-quality habitats should occur when reproductive success in the highand the low-quality habitats becomes equal (Brown 1969; Fretwell and Lucas 1969); however, individuals may be excluded from the high-quality habitat before reproductive success has declined to that extent (Dhondt et al. 1992; Ferrer and Donazar 1996; Blanco et al. 1998). In either case, the population consequence is that per capita reproductive success declines, which has a stabilizing effect on population size. The ultimate reason why individuals let themselves be excluded must lie in the costs and benefits associated with territory defense in different habitats. If we could measure these costs and benefit curves as a function of both territory size and habitat and/or individual quality, we would be able to predict the distribution of individuals over their habitats, their individual territory size, and both reproductive success and mortality. Because individuals are likely to defend only an optimal territory size, given the cost and benefit curves for their individual circumstances, we cannot derive these cost and benefit 
curves from variation in their actual territory size (see appendix). Cost and benefit curves of territory size and habitat quality are thus, in practice, very difficult to measure, and models of population dynamics based on these estimated curves are of low practical use.

Knowledge of the relative effects of food and nest sites (or other resources) would help in predicting whether either a density-dependent decline in reproductive success or density-dependent territorial exclusion is more important. As we have shown, when nest sites limit the breeding density, a territorial system is expected in which only these nest sites are defended and reproductive success is likely to be mostly density independent. More precisely, reproductive success is density independent within a habitat of equal quality, but across habitats of different quality, the mean reproductive success can be density dependent (Dhondt et al. 1992; Ferrer and Donazar 1996; Blanco et al. 1998). The general expectation is that species (or pop- ulations) with small noncontiguous territories will be limited by nest sites or other nondivisible resources, and these species will show both a density-dependent probability of breeding and density-independent reproductive success (fig. 1, pied flycatcher). In contrast, species with large contiguous territories will have density-dependent reproduction and are likely to have a weaker density-dependent exclusion of potential breeding individuals (fig. 1, great tit).

\section{Acknowledgments}

Data on foraging distances were collected by S. Kamphuis and S. van Dijk. Constructive comments on earlier drafts were given by M. Lambrechts, J. Tinbergen, A. van Noordwijk, and an anonymous referee. C.B. is supported by a grant to M.E.V. from ALW-NWO, the life sciences program of the Netherlands Organization for Scientific Research. 


\section{APPENDIX}

\section{Why Is It Difficult to Measure the Cost and Benefit Curves of Territory Size?}

Our models are based on costs and benefits that are associated with territory size. Although these curves are theoretically feasible, they are in practice almost impossible to measure. The reason is that, given the population size, the variation in territory size is due to variation in $d$ and/ or $b$ because each individual will defend the territory size optimal for its own cost and benefit curves (fig. A1). If the cause of territory size variation is due to variation in benefit curves $(b)$, we measure a linear or even exponential benefit curve instead of the asymptotic curve that we theoretically expect (fig. A1A). Variation in territory size through between individual variation in $d$ gives a cost curve that declines instead of increases (fig. A1B). In these two examples, we varied either the cost or the benefit curve and in this way are able to measure the other curve correctly (the cost curve in fig. A1A and the benefit curve in fig. A1 $B)$. We may be able to manipulate one curve through food supplementation or removal of competitors and then measure the other curve, but curves may not be independent of one another. If there is a positive relationship between the ability to defend a territory $(d)$ and the foraging efficiency $(b)$, neither the real cost nor the benefit curve can be measured (fig. A1C). Alternatively, if there is a negative relationship between territory defense $(d)$ and foraging efficiency $(b)$, the resulting costs and benefits, as a function of territory size, become even more difficult to interpret (fig. A1D). In this latter graph, individuals with curves of either low cost and high benefit or high cost and
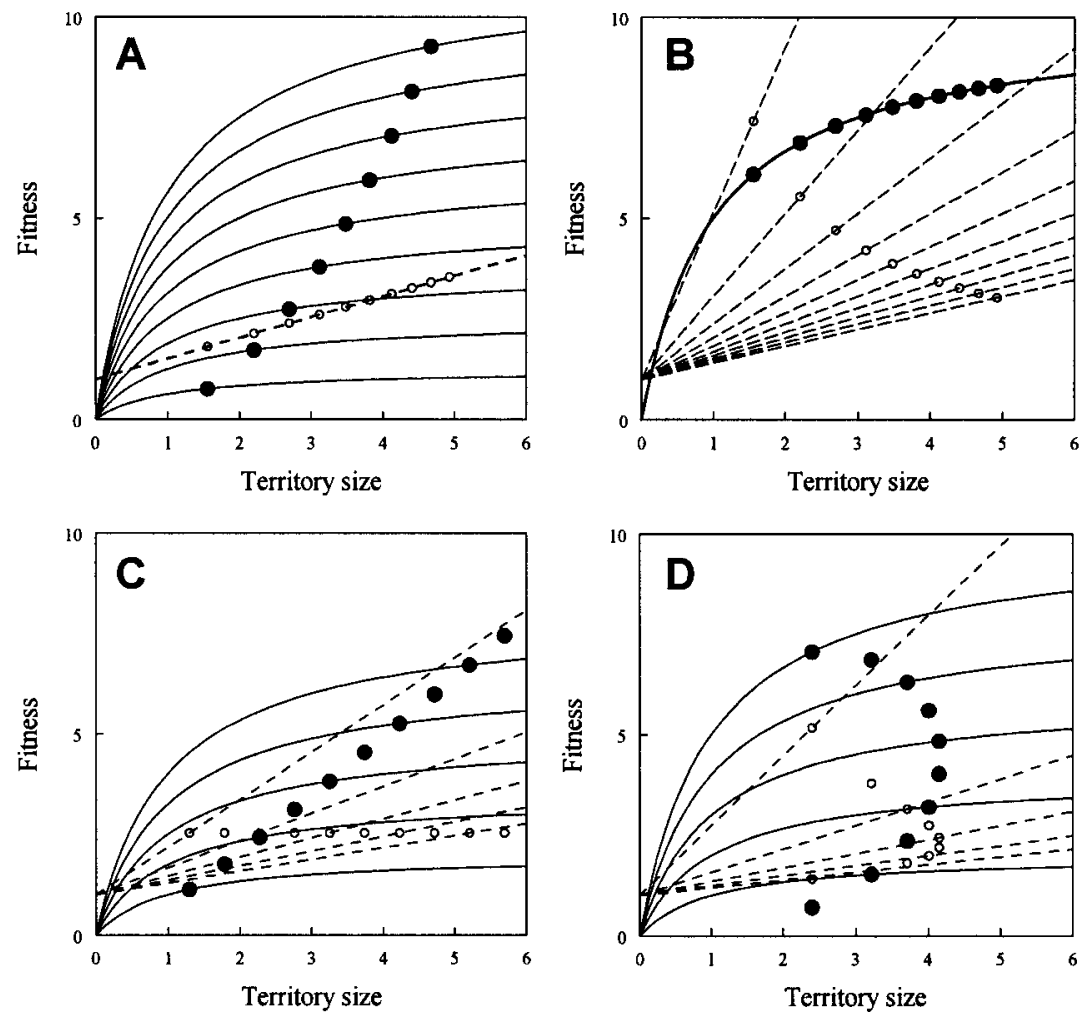

Figure A1: Resultant costs (open dots) and benefits (solid dots) as function of the optimal territory size when variation in territory size is due to variation in costs and/or benefit curves. A, Variation in benefit curves and not in cost curves (foraging efficiency, $b$, varies from 1.25 to 7.50). $B$, Variation in cost curves and not in benefit curves (ability to defend, $d$, varies from 0.25 to 2.50). C, Variation in both benefit and cost curves, and the slopes of both curves are positively related ( $b$ varies from 2 to 8.75 in steps of $0.75, d$ varies from 0.40 to 1.75 in steps of 0.15 , and $b=5 d$ ). $D$, Variation in both benefit and cost curves; the slopes of both curves are negatively related ( $b$ varies from 1 to 11 in steps of $1, d$ varies from 0.5 to 5.0 in steps of 0.50 , and $d=5-[.5 \times b]$ ). We simulated a population with 10 individuals on a fixed surface, with varying $b$ and $d$. Optimal territory sizes were calculated according to equations (1)-(4), and $f(N-1)$ was solved by iteration until the sum of the territory sizes equaled the total surface. The other constants in the simulations were $M=1$ and total area $=35$. We plotted the benefit (solid) and cost (striped) curves in each graph. For clarity, we plotted only half of these cost and benefit curves in $C$ and $D$. These results do not change qualitatively when different formulations of the benefit curves are used (e.g., Stamps and Krishnan 2001), as long as they increase with a diminishing return. 
low benefit have small territories, while the individual with an intermediate cost benefit has the largest territory size. Although this result strongly depends on the parameters of the model, it shows that there may be no simple correlation between costs or benefits and territory size. The resultant costs and benefits as a function of territory size are expected to depend on different curves that are not easily measured.

The difficulty in measuring cost and benefits of territory size can be illustrated in our study of fitness consequences of territory size in great tits (Both and Visser 2000). We enlarged territories of individuals varying initially in territory size by removing one or more of their neighbors, thus manipulating the costs rather then the benefits. As expected, the costs of territory defense declined, as measured by a negative correlation between mortality and the extent of territory enlargement. We did not manipulate the benefit curve and therefore expected to find a positive curve with a decelerating slope. The actual benefits (measured as the number of young recruited into the breeding population) were linearly or even slightly exponentially related to territory size, contrary to our theoretical expectation (Both and Visser 2000). We think that by reducing the costs and thereby giving the birds a larger territory, the birds with the largest territories could choose a nesting site in their territory with the highest local density of food. This is supported by a negative correlation between the average foraging distance and territory size for a small part of the manipulated territories $\left(r_{\mathrm{s}}=-0.90\right.$, $n=6, P=.015)$ that was expected to be positive under our assumptions of a homogeneous habitat. In this case, the benefit and cost curves were correlated, and none could be measured.

\section{Literature Cited}

Alatalo, R. V., and A. Lundberg. 1984. Density-dependence in breeding success of the pied flycatcher (Ficedula hypoleuca). Journal of Animal Ecology 53:969-977.

Arcese, P., and J. N. M. Smith. 1988. Effects of population density and supplemental food on reproduction in song sparrows. Journal of Animal Ecology 57:119-136.

Arcese, P., J. N. M. Smith, W. M. Hochachka, C. M. Rogers, and D. Ludwig. 1992. Stability, regulation, and the determination of abundance in an insular song sparrow population. Ecology 73:805-822.

Blanco, G., J. A. Fargallo, J. A. Cuevas, and J. L. Tella. 1998. Effects of nest-site availability and distribution on density-dependent clutch size and laying date in the chough Pyrrhocorax pyrrhocorax. Ibis 140:252-256.

Both, C. 1998a. Density dependence of clutch size: habitat heterogeneity or individual adjustment? Journal of Animal Ecology 67:659-666.
. 1998b. Experimental evidence for density dependence of reproduction in great tits. Journal of Animal Ecology 67:667-674.

- 2000. Density dependence of avian clutch size in resident and migrant species: is there a constraint on the predictability of competitor density? Journal of Avian Biology 31:412-417.

Both, C., and M. E. Visser. 2000. Breeding territory size affects fitness: an experimental study on competition at the individual level. Journal of Animal Ecology 69: 1021-1030.

Both, C., J. M. Tinbergen, and M. E. Visser. 2000. Adaptive density dependence of avian clutch size. Ecology 81: 3391-3403.

Brown, J. L. 1964. The evolution of diversity in avian territorial systems. Wilson Bulletin 76:160-169.

- 1969. The buffer effect and productivity in tit populations. American Naturalist 103:347-354.

Catterall, C. P., W. S. Wyatt, and L. J. Henderson. 1982. Food resources, territory density and reproductive success of an island silvereye population Zosterops lateralis. Ibis 124:405-421.

Charles, J. K. 1972. Territorial behaviour and the limitation of population size in crows, Corvus corone and Corvus cornix. Ph.D. thesis. University of Aberdeen.

Davies, N. B., and A. I. Houston. 1981. Owners and satellites: the economics of territory defense in the pied wagtail Motacilla alba. Journal of Animal Ecology 50: 157-180.

- 1984. Territory economics. Pages 148-169 in J. R. Krebs and N. B. Davies, eds. Behavioural ecology, an evolutionary approach. Blackwell, Oxford.

Dhondt, A. A., and R. Eyckerman. 1980. Competition between the great and the blue tit outside the breeding season in field experiments. Ecology 61:1291-1296.

Dhondt, A. A., J. Schillemans, and J. De Laet. 1982. Blue tit territories in populations at different density levels. Ardea 70:185-188.

Dhondt, A. A., B. Kempenaers, and F. Adriaensen. 1992. Density-dependent clutch size caused by habitat heterogeneity. Journal of Animal Ecology 61:643-648.

Doutrelant, C., J. Blondel, P. Perret, and M. M. Lambrechts. 2000. Blue tit song repertoire size, male quality and interspecific competition. Journal of Avian Biology 31:360-366.

Ferrer, M., and J. A. Donazar. 1996. Density-dependent fecundity by habitat heterogeneity in an increasing population of Spanish imperial eagles. Ecology 77:69-74.

Fretwell, S., and H. L. Lucas. 1969. On territorial behavior and other factors influencing habitat distribution in birds. 1. Theoretical development. Acta Biotheoretica 19:16-36.

Gill, F. B., and L. L. Wolf. 1975. Economics of feeding 
territoriality in the golden-winged sunbird. Ecology 56: 333-345.

Hinde, R. A. 1952. The behaviour of the great tit and some other related species. Behaviour 2(suppl.):1-201.

- 1956. The biological significance of territories in birds. Ibis 98:340-369.

Kluyver, H. N. 1951. The population ecology of the great tit, Parus m. major L. Ardea 39:1-135.

Kluyver, H. N., and L. Tinbergen. 1953. Territory and the regulation of density in titmice. Archives Neerlandais Zoologie 10:265-289.

Krebs, J. R. 1971. Territory and breeding density in the great tit, Parus major. Ecology 52:2-22.

Lack, D. 1966. Population studies of birds. Oxford University Press, Oxford.

Lemon, W. C. 1993. Heritability of selectively advantageous foraging behaviour in a small passerine. Evolutionary Ecology 7:421-428.

Löhrl, H. 1987. Zum Territorialverhaltven der Kohlmeise (Parus major) Mehrere Bruten gleichzeitig an demselben Baum. Vogelwelt 108:221-223.

Minot, E. O., and C. M. Perrins. 1986. Interspecific interference competition-nest sites for blue and great tits. Journal of Animal Ecology 55:331-350.

Newton, I. 1988. A key factor analysis of a sparrowhawk population. Oecologia (Berlin) 76:588-596.

- 1992. Experiments on the limitation of bird numbers by territorial behaviour. Biological Reviews of the Cambridge Philosophical Society 67:129-173.

Nilsson, S. G. 1987. Limitation and regulation of population density in the nuthatch Sitta europaea (Aves) breeding in natural cavities. Journal of Animal Ecology 56:921-937.

Orians, G. H., and N. E. Pearson. 1979. On the theory of central place foraging. Pages 155-177 in D. F. Horn, ed. Analysis of ecological systems. Ohio State University Press, Columbus.

Rodenhouse, N. L., T. W. Sherry, and R. T. Holmes. 1997. Site-dependent regulation of population size: a new synthesis. Ecology 78:2025-2042.

Schoener, T. W. 1983. Simple models of optimal feedingterritory size: a reconciliation. American Naturalist 121: 608-629.

Smith, J. N. M., P. Arcese, and W. M. Hochachka. 1991.
Social behavior and population regulation in insular bird populations: implications for conservation. Pages 148-167 in C. M. Perrins, J. D. Lebreton, and G. J. M. Hirons, eds. Bird population studies. Oxford University Press, Oxford.

Southern, H. N. 1970. The natural control of a population of tawny owls (Strix aluco). Journal of Zoology (London) 162:197-285.

Stamps, J. A., and V. V. Krishnan. 2001. How territorial animals compete for divisible space: a learning-based model with unequal competitors. American Naturalist 157:154-169.

Stenning, M. J., P. H. Harvey, and B. Campbell. 1988. Searching for density-dependent regulation in a population of the pied flycatcher Ficedula hypoleuca Pallas. Journal of Animal Ecology 57:307-317.

Tompa, F. S. 1967. Reproductive success in relation to breeding density in pied flycatchers, Ficedula hypoleuca. Acta Zoologici Fennici 118:1-28.

van Balen, J. H. 1973. A comparative study of the breeding ecology of the great tit Parus major in different habitats. Ardea 61:1-93.

van Balen, J. H., and R. P. J. Potting. 1990. Comparative reproductive biology of four blue tit populations in the Netherlands. Pages 19-38 in J. Blondel, A. G. Gosler, J. D. Lebreton, and R. H. McCleery, eds. Population biology of passerine birds: an integrated approach. Springer, Berlin.

Village, A. 1983. The role of nest-site availability and territorial behaviour in limiting breeding density in kestrels. Journal of Animal Ecology 52:635-645. . 1990. The kestrel. Poyser, London.

von Haartman, L. 1956. Territory in the pied flycatcher. Ibis 98:460-475.

Watson, A., and R. Moss. 1970. Dominance spacing behaviour and aggression in relation to population limitation in vertebrates. Pages 167-223 in A. Watson, ed. Animal populations in relation to their food resources. Blackwell, Oxford.

Wesolowski, T., L. Tomialojc, and T. Stawarczyk. 1987. Why low numbers of Parus major in Bialowieza Forest-removal experiments. Acta Ornithologica 23: 303-316.

Associate Editor: Trevor Price 